\title{
BMJ Open Outcome of patients admitted with acute coronary syndrome on palliative treatment: insights from the nationwide AMIS Plus Registry 1997-2014
}

\author{
Paul Erne, ${ }^{1,2}$ Dragana Radovanovic, ${ }^{1}$ Burkhardt Seifert, ${ }^{3}$ Osmund Bertel, ${ }^{4}$ \\ Philip Urban, ${ }^{5}$ on behalf of the AMIS Plus Investigators
}

To cite: Erne $P$,

Radovanovic D, Seifert B, et al. Outcome of patients admitted with acute coronary syndrome on palliative treatment: insights from the nationwide AMIS Plus Registry 1997-2014. BMJ Open 2015;5:e006218. doi:10.1136/bmjopen-2014006218

- Prepublication history for this paper is available online. To view these files please visit the journal online (http://dx.doi.org/10.1136/ bmjopen-2014-006218).

Received 28 July 2014 Revised 7 January 2015 Accepted 20 January 2015

CrossMark

For numbered affiliations see end of article.

Correspondence to Professor Paul Erne; paul.erne@erne-net.ch

\section{ABSTRACT}

Objective: Compliance with guidelines is increasingly used to benchmark the quality of hospital care, however, very little is known on patients admitted with acute coronary syndromes (ACS) and treated palliatively. This study aimed to evaluate the baseline characteristics and outcomes of these patients.

Design: Prospective cohort study.

Setting: Eighty-two Swiss hospitals enrolled patients from 1997 to 2014.

Participants: All patients with ACS enrolled in the AMIS Plus registry ( $n=45091$ ) were analysed according to three treatment groups: palliative treatment, defined as use of aspirin and analgesics only and no reperfusion; conservative treatment, defined as any treatment including antithrombotics or anticoagulants, heparins, P2Y ${ }_{12}$ inhibitors, GPIlb/lla but no pharmacological or mechanical reperfusion; and reperfusion treatment (thrombolysis and/or percutaneous coronary intervention during initial hospitalisation). The primary outcome measure was in-hospital mortality and the secondary measure was 1 -year mortality.

Results: Of the patients, 1485 (3.3\%) were palliatively treated, $11119(24.7 \%)$ were conservatively treated and $32487(72.0 \%)$ underwent reperfusion therapy. In 1997, $6 \%$ of all patients were treated palliatively and this continuously decreased to $2 \%$ in 2013. Baseline characteristics of palliative patients differed in comparison with conservatively treated and reperfusion patients in age, gender and comorbidities (all $\mathrm{p}<0.001$ ). These patients had more in-hospital complications such as postadmission onset of cardiogenic shock ( $15.6 \%$ vs $5.2 \% ; p<0.001)$, stroke $(1.8 \%$ vs $0.8 \% ; p=0.001)$ and a higher in-hospital mortality ( $25.8 \%$ vs $5.6 \%$; $p<0.001)$.

The subgroup of patients followed 1 year after discharge $(\mathrm{n}=8316)$ had a higher rate of reinfarction $(9.2 \%$ vs $3.4 \% ; p=0.003)$ and mortality ( $14.0 \%$ vs $3.5 \%$; $p<0.001)$.

Conclusions: Patients with ACS treated palliatively were older, sicker, with more heart failure at admission and very high in-hospital mortality. While refraining from more active therapy may often constitute the most humane and appropriate approach, we think it is important to also evaluate these patients and include them in registries and outcome evaluations.

\section{Strengths and limitations of this study}

- This is the first study presenting characteristics and outcomes of a large cohort of patients admitted for acute coronary syndrome (ACS) and treated only palliatively. It compares the differences in baseline characteristics and outcomes in hospital and 1 year after discharge of these patients with patients treated conservatively or with reperfusion therapy.

- Whereas it may often be completely appropriate to provide restrictive and palliative care only for elderly patients with very poor prognosis, this study shows a much larger grey zone of decision-making.

- With this study, it was not possible to find evidence of the exact reasons for withholding active therapy by only treating patients palliatively.

- This study showed that an international consensus should be reached on whether such patients should be included in the overall evaluation of patients with ACS outcomes.

Clinical trial number: ClinicalTrials.gov Identifier: NCT01 305785.

\section{INTRODUCTION}

Guideline recommended strategies are derived from prospective randomised trials and expert consensus. This may result in bias since the therapies are only studied in patients who consent and do not have exclusion criteria. Thus, very little is known on an important subgroup of patients who at the time of admission for various reasons received restricted or palliative treatment only. Reasons for withholding comprehensive and/or invasive therapy may be a very limited life expectancy, advanced age or severe comorbidity. These patients are not represented in 
prospective trials and often not included in registries. They are a poorly defined group in terms of presentation characteristics and outcome, but they might have a profound influence on outcome statistics, benchmarking and resource utilisation.

Since 1997, we have followed diagnostic and treatment strategies in a long-term nationally based registry in which all patients are included once a hospital decides to collaborate for a defined period of time. The present details of the registry and participants have been described recently. ${ }^{1-3}$

Patients were assigned to one of three groups according to the therapy received. We present characteristics and outcomes of a large cohort of patients admitted to Swiss hospitals with acute coronary syndrome (ACS) who received primary palliative treatment.

\section{METHODS}

The AMIS Plus project is an ongoing nationwide prospective registry of patients with ACS admitted to hospitals in Switzerland, supported by the Swiss Societies of Cardiology, Internal Medicine and Intensive Care Medicine. It was founded in 1997 with the goal to understand the transfer, use and practicability of knowledge gained from randomised trials and to generate data for the planning of subsequent prospective and randomised studies. Details have been previously published. ${ }^{1}$ Of 106 hospitals treating ACS in Switzerland, 82 temporarily or continuously enrolled patients in AMIS Plus. Participating centres, ranging from community institutions to large tertiary facilities, provide blinded data for each patient through standardised internet-based or paper-based questionnaires. Participating centres are strongly encouraged to enrol all patients fulfilling the inclusion criteria to avoid selection bias. Hospital data are provided and completed by the treating physician or a trained study nurse. All data are checked for completeness, plausibility and consistency by the AMIS Plus Data Centre in the Epidemiology, Biostatistics and Prevention Institute at the University of Zurich, and treating physicians or study nurses are queried when necessary. Centres are randomly audited and the quality of data checked by the Clinical Trials Unit on an annual basis since 2011.

In this study, patients with ACS were divided into groups according to the therapy received during the initial hospitalisation: palliative treatment, defined as use of aspirin and analgesics only, without the use of any other antithrombotics, anticoagulants, heparins, P2Y12

Table 1 Baseline characteristics of patients with ACS according to treatment $(\mathrm{N}=45091)$

\begin{tabular}{|c|c|c|c|c|}
\hline & Palliative & Conservative & Reperfusion & $\begin{array}{l}\text { p Value } \\
\text { palliative } \\
\text { vs others }\end{array}$ \\
\hline Number of patients & $1485(3.3 \%)$ & $11119(24.7 \%)$ & 32487 (72.0\%) & \\
\hline Sex, male (\%) & $867(58.4)$ & $7113(64.0)$ & 24844 (76.5) & $<0.001$ \\
\hline Age in years, mean (SD) & $76.7(12.3)$ & $72.3(12.9)$ & $63.5(12.4)$ & $<0.001$ \\
\hline Delay median (IQR) & $\begin{array}{l}305 \min (120 \\
984 \min )\end{array}$ & $\begin{array}{l}350 \min (135 \\
1005 \min )\end{array}$ & $\begin{array}{l}209 \min \\
(105540 \mathrm{~min})\end{array}$ & $<0.001$ \\
\hline $\begin{array}{l}\text { Resuscitation prior to admission } \\
\text { Symptoms at admission }\end{array}$ & $84 / 1465(5.7)$ & 1388/10 992 (3.5) & 1708/32 065 (5.3) & 0.14 \\
\hline Pain (\%) & 930/1363 (68.2) & $8584 / 10674(80.4)$ & 27 415/30 911 (88.7) & $<0.001$ \\
\hline Dyspnoea (\%) & 646/1266 (51.0) & $4014 / 10138$ (39.6) & $7034 / 28607$ (24.6) & $<0.001$ \\
\hline Atrial fibrillation & 228/1205 (18.9) & 784/8272 (9.5) & $996 / 29444$ (3.4) & $<0.001$ \\
\hline STEMI (\%) & $585(39.4)$ & $4578(41.2)$ & $20393(62.8)$ & $<0.001$ \\
\hline Killip classes 3/4 (\%) & $266 / 1457$ (18.3) & $1182 / 10971$ (10.8) & 1780/32 $057(5.6)$ & $<0.001$ \\
\hline Hypertension (\%) & $984 / 1353$ (72.7) & $7046 / 10620$ (66.3) & $17576 / 30931$ (56.8) & $<0.001$ \\
\hline Diabetes (\%) & 420/1372 (30.6) & $2795 / 10753(26.0)$ & $5599 / 31234$ (17.9) & $<0.001$ \\
\hline Dyslipidaemia (\%) & $576 / 1124$ (51.2) & $5194 / 9642$ (53.9) & 17 237/29 302 (58.8) & $<0.001$ \\
\hline Current smoker (\%) & $255 / 1210(21.1)$ & $2779 / 10123(27.5)$ & $12817 / 30069$ (42.6) & $<0.001$ \\
\hline Obesity (BMI>30) (\%) & $185 / 983(18.8)$ & $1559 / 8413(18.5)$ & $5786 / 27653(20.9)$ & $<0.001$ \\
\hline Coronary artery disease (\%) & $675 / 1334(50.6)$ & $460 / 9658(47.8)$ & 9980/30 832 (32.4) & $<0.001$ \\
\hline Heart failure $(\%)$ & $145 / 1061(13.7)$ & $535 / 6692(8.0)$ & $538 / 26742(2.0)$ & $<0.001$ \\
\hline Cerebrovascular disease (\%) & $150 / 1062(14.1)$ & $710 / 6741(10.5)$ & $1237 / 27504(4.5)$ & $<0.001$ \\
\hline Hemiplegia (\%) & $23 / 1061(2.2)$ & $103 / 6692(1.5)$ & $108 / 26742(0.4)$ & $<0.001$ \\
\hline Dementia (\%) & $87 / 1061$ (8.2) & $375 / 6692(5.6)$ & $187 / 26742(0.7)$ & $<0.001$ \\
\hline Chronic lung disease (\%) & $121 / 1062(11.4)$ & $696 / 6741$ (10.3) & $1280 / 27504(4.7)$ & $<0.001$ \\
\hline Moderate to severe liver disease (\%) & $22 / 1062(2.1)$ & $63 / 6741(0.9)$ & $118 / 27310(0.4)$ & $<0.001$ \\
\hline Moderate to severe renal disease (\%) & 223/1062 (21.0) & $1013 / 6741(15.0)$ & $1213 / 27504(4.4)$ & $<0.001$ \\
\hline Cancer disease (\%) & 120/1062 (11.3) & $572 / 6700(8.5)$ & $1331 / 26794(5.0)$ & $<0.001$ \\
\hline Charlson Comorbidity Index >1 (\%) & $577 / 1061(54.4)$ & $2791 / 6692(41.7)$ & $4901 / 26742$ (18.3) & $<0.001$ \\
\hline
\end{tabular}


inhibitors, GPIIb/IIIa inhibitors and no pharmacological or mechanical reperfusion; conservative treatment, defined as any treatment including antithrombotics or anticoagulants, heparins, $\mathrm{P}_{2} \mathrm{Y}_{12}$ inhibitors (clopidogrel, prasugrel or ticagrelor), GPIIb/IIIa but no pharmacological or mechanical reperfusion; and reperfusion treatment, including thrombolysis and/or percutaneous coronary intervention (PCI).

Comorbidities of the patients were assessed using the weighted Charlson Index. ${ }^{4}$ Risk factors were documented in the patient's medical history: dyslipidaemia, arterial hypertension and diabetes were assigned if the patient had been previously treated and/or diagnosed by a physician. Documentation of the risk factors provided by the local physicians was accepted as stated. Patients were defined as obese if the body mass index was $\geq 30 \mathrm{~kg} / \mathrm{m}^{2}$ and as smokers if the patient was a current smoker at the time of the cardiovascular event.

For the present analysis, the primary outcome measure was in-hospital mortality and the secondary outcome measure was 1-year mortality after discharge. Additionally, the major adverse cardiac and cerebrovascular events in-hospital (MACCE-composite end point of reinfarction, stroke and/or death) and adverse cardiac and cerebrovascular events during follow-up (MACCE-composite end point of reinfarction, stroke, any reinterventions and/or death) were assessed.

\section{Patient selection}

The present analysis included all patients with ACS enrolled in AMIS Plus between January 1997 and April 2014. ACS included acute myocardial infarction (AMI), defined according to the universal definitions of MI by characteristic symptoms and/or ECG changes and cardiac marker elevation (either creatine kinase MB fraction at least twice the upper limit of normal or troponin I or $\mathrm{T}$ above individual hospital cut-off levels for $\mathrm{MI}$ ), and unstable angina (symptoms or ECG changes compatible with ACS and cardiac marker levels lower than cut-off or normal levels). ${ }^{6}$ Classification of ST-elevation myocardial infarction (STEMI) included evidence of AMI as above and ST-segment elevation and/or new left bundle branch block on the initial ECG. Non-STEMI (NSTEMI) included patients with ischaemic symptoms, ST-segment depression or T-wave abnormalities in the absence of ST elevation on the initial ECG.

Since 2006, patients from 59 centres were asked for written consent to a telephone follow-up contact 12 months after discharge.

\section{Statistical analysis}

Continuous variables are expressed as means \pm 1 SD or medians with IQR and were compared between groups using the Mann-Whitney U test. Categorical data are presented as percentages and compared between groups using Pearson's $\chi^{2}$ test. The Breslow-Day test of homogeneity of the OR was used to identify subgroups of patients with a particularly high reduction of palliative treatment between

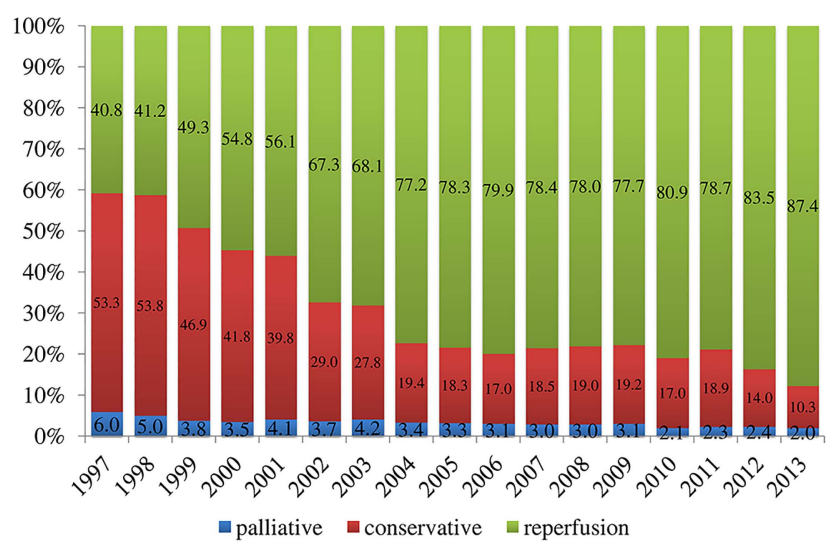

Figure 1 Temporal trends of treatments, 1997-2014.

time periods. Linear regression was used to analyse trends in age over time and differences between trends of patients treated palliatively and those treated otherwise. Two-sided p Values less than 0.05 were considered statistically significant. All analyses were performed using IBM SPSS Statistics (V.22, Armonk, New York: IBM Corp.)

\section{RESULTS}

Between January 1997 and April 2014, 45279 patients with ACS from 82 Swiss hospitals were enrolled in the AMIS Plus registry. The data on the therapies received were missing for $188(0.4 \%)$ patients. Therefore, complete data were available from 45091 patients. Among these patients, $72 \%$ underwent reperfusion, $24.7 \%$ were treated conservatively and $3.3 \%$ palliatively.

The baseline characteristics according to therapy received during the index hospitalisation are shown in table 1.

The patients with ACS treated palliatively differed in all baseline characteristics from the patients treated conservatively as well as the patients who received thrombolytic therapy or underwent PCI. They were older, predominantly women, with more risk factors such as hypertension, and suffered more frequently from diabetes, heart failure, cerebrovascular diseases, renal

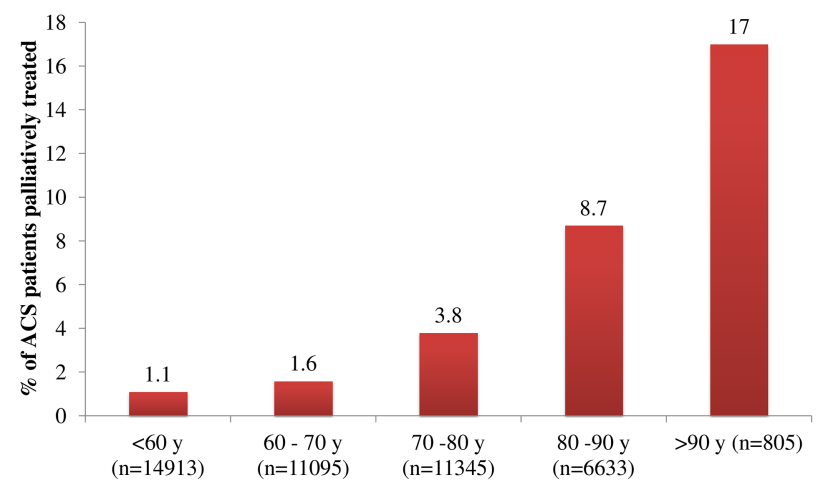

Figure 2 Palliatively treated patients with acute coronary syndrome (ACS) according to age categories. 
Table 2 Trends in baseline characteristics of patients with ACS according to treatment ( $N=45091)$

\begin{tabular}{|c|c|c|c|c|c|c|c|c|c|c|c|c|c|c|c|c|c|}
\hline & \multicolumn{4}{|c|}{ Palliative $(n=1485)$} & \multirow[b]{2}{*}{$\begin{array}{l}P \text { for } \\
\text { trends }\end{array}$} & \multirow{2}{*}{$\begin{array}{l}P \text { for } \\
\text { difference in } \\
\text { trends vs } \\
\text { reperfusion }\end{array}$} & \multicolumn{4}{|c|}{ Conservative $(n=11119)$} & \multirow[b]{2}{*}{$\begin{array}{l}\mathrm{P} \text { for } \\
\text { trends }\end{array}$} & \multirow{2}{*}{$\begin{array}{l}\text { P for } \\
\text { difference in } \\
\text { trends vs } \\
\text { reperfusion }\end{array}$} & \multicolumn{4}{|c|}{ Reperfusion ( $n=32$ 487) } & \multirow[b]{2}{*}{$\begin{array}{l}P \text { for } \\
\text { trends }\end{array}$} \\
\hline & $\begin{array}{l}1997- \\
2001\end{array}$ & $\begin{array}{l}2002- \\
2005\end{array}$ & $\begin{array}{l}2006- \\
2009\end{array}$ & $\begin{array}{l}2010- \\
2013\end{array}$ & & & $\begin{array}{l}1997- \\
2001\end{array}$ & $\begin{array}{l}2002- \\
2005\end{array}$ & $\begin{array}{l}2006- \\
2009\end{array}$ & $\begin{array}{l}2010- \\
2013\end{array}$ & & & $\begin{array}{l}1997- \\
2001\end{array}$ & $\begin{array}{l}2002- \\
2005\end{array}$ & $\begin{array}{l}2006- \\
2009\end{array}$ & $\begin{array}{l}2010- \\
2013\end{array}$ & \\
\hline $\begin{array}{l}\text { Number of } \\
\text { patients }\end{array}$ & 414 & 416 & 382 & 273 & & & 4337 & 2629 & 2277 & 1876 & & & 4398 & 8411 & 9742 & 9936 & \\
\hline Males & 65.5 & 56.3 & 52.6 & 59.0 & 0.018 & 0.003 & 67.6 & 61.4 & 60.3 & 63.8 & $<0.001$ & $<0.001$ & 76.6 & 76.9 & 76.6 & 75.6 & 0.19 \\
\hline $\begin{array}{l}\text { Age in years, } \\
\text { mean (SD) }\end{array}$ & $78.8(12)$ & $77.8(12)$ & $80.6(11)$ & $75.5(13)$ & $<0.001$ & $<0.001$ & $68.9(13)$ & 74.6 (12) & $75.8(13)$ & $73.1(13)$ & $<0.001$ & $<0.001$ & $62.2(12)$ & $62.9(12)$ & $63.5(12)$ & $64.7(13)$ & $<0.001$ \\
\hline $\begin{array}{l}\text { Resuscitation } \\
\text { prior to } \\
\text { admission }\end{array}$ & 8.7 & 6.1 & 3.1 & 4.4 & 0.002 & 0.011 & 5.2 & 2.4 & 2.0 & 3.1 & $<0.001$ & $<0.001$ & 5.9 & 4.4 & 5.2 & 6.0 & 0.019 \\
\hline \multicolumn{18}{|c|}{ Symptoms at admission } \\
\hline Pain & 81.6 & 57.8 & 66.3 & 67.3 & $<0.001$ & $<0.001$ & 87.4 & 72.5 & 76.4 & 80.5 & $<0.001$ & $<0.001$ & 93.2 & 78.3 & 90.3 & 94.4 & $<0.001$ \\
\hline Dyspnoea & 54.9 & 45.7 & 54.5 & 49.4 & 0.68 & $<0.001$ & 31.6 & 41.2 & 46.1 & 47.1 & $<0.001$ & $<0.001$ & 21.3 & 17.2 & 26.4 & 31.6 & $<0.001$ \\
\hline Atrial fibrillation & 18.8 & 18.6 & 19.4 & 18.8 & 0.93 & 0.50 & 7.9 & 10.1 & 10.4 & 8.9 & 0.40 & 0.001 & 3.4 & 3.1 & 3.1 & 4.0 & 0.005 \\
\hline STEMI & 51.0 & 41.1 & 32.2 & 29.3 & $<0.001$ & 0.083 & 48.6 & 39.4 & 35.7 & 33.0 & $<0.001$ & $<0.001$ & 78.8 & 63.5 & 59.5 & 58.2 & $<0.001$ \\
\hline Killip classes 3/4 & 22.3 & 17.8 & 16.4 & 15.6 & 0.019 & 0.002 & 10.0 & 12.0 & 11.1 & 10.3 & 0.53 & $<0.001$ & 5.3 & 4.1 & 5.7 & 6.8 & $<0.001$ \\
\hline Hypertension & 62.0 & 71.5 & 81.3 & 79.4 & $<0.001$ & 0.033 & 55.0 & 70.4 & 76.7 & 75.0 & $<0.001$ & $<0.001$ & 47.4 & 54.5 & 59.5 & 60.4 & $<0.001$ \\
\hline Diabetes & 27.9 & 32.4 & 34.2 & 27.2 & 0.75 & 0.13 & 23.0 & 28.6 & 29.0 & 25.8 & $<0.001$ & 0.001 & 16.6 & 17.8 & 17.7 & 18.9 & 0.002 \\
\hline Dyslipidaemia & 47.2 & 51.6 & 48.9 & 60.1 & 0.013 & 0.011 & 50.7 & 57.2 & 52.7 & 58.4 & $<0.001$ & $<0.001$ & 57.8 & 64.3 & 53.9 & 59.3 & 0.001 \\
\hline Current smoker & 27.6 & 17.2 & 14.7 & 25.1 & 0.088 & 0.001 & 33.0 & 22.9 & 22.7 & 26.1 & $<0.001$ & $<0.001$ & 45.6 & 43.7 & 41.8 & 41.6 & $<0.001$ \\
\hline Obesity (BMl>30) & 15.9 & 18.8 & 18.8 & 21.8 & 0.16 & 0.98 & 19.0 & 16.9 & 18.6 & 19.9 & 0.46 & 0.009 & 17.8 & 19.8 & 21.1 & 22.8 & $<0.001$ \\
\hline CAD & 56.8 & 52.4 & 50.7 & 40.2 & $<0.001$ & 0.068 & 46.6 & 51.6 & 51.0 & 40.4 & 0.003 & $<0.001$ & 34.9 & 32.4 & 34.3 & 29.6 & $<0.001$ \\
\hline Heart failure & 23.5 & 15.9 & 14.6 & 7.8 & 0.001 & 0.039 & 12.4 & 9.3 & 8.1 & 5.7 & $<0.001$ & 0.030 & 3.1 & 2.3 & 1.8 & 2.0 & 0.083 \\
\hline $\begin{array}{l}\text { Cerebrovascular } \\
\text { disease }\end{array}$ & 17.6 & 13.4 & 14.3 & 14.5 & 0.87 & 0.74 & 8.8 & 11.6 & 10.0 & 9.9 & 0.16 & 0.049 & 5.5 & 4.5 & 4.0 & 5.0 & 0.12 \\
\hline Dementia & 5.9 & 6.6 & 9.4 & 9.3 & 0.14 & 0.47 & 2.1 & 5.1 & 6.2 & 5.9 & 0.050 & 0.008 & 1.2 & 0.5 & 0.6 & 0.7 & 0.004 \\
\hline Lung disease & 14.7 & 14.1 & 8.3 & 11.2 & 0.12 & 0.13 & 16.6 & 10.8 & 10.0 & 9.4 & 0.014 & 0.47 & 9.2 & 4.7 & 4.4 & 4.7 & 0.44 \\
\hline Renal disease & 11.8 & 17.4 & 24.8 & 22.3 & 0.034 & 0.16 & 11.4 & 12.0 & 18.1 & 15.7 & $<0.001$ & $<0.001$ & 2.8 & 3.6 & 4.1 & 5.4 & $<0.001$ \\
\hline Cancer disease & 11.8 & 10.6 & 12.4 & 10.8 & 0.91 & 0.25 & 5.7 & 9.0 & 8.5 & 8.3 & 0.81 & 0.001 & 7.1 & 4.5 & 4.3 & 6.0 & $<0.001$ \\
\hline $\mathrm{CCl}>1$ & 55.9 & 54.5 & 57.3 & 50.0 & 0.33 & 0.020 & 39.4 & 41.5 & 44.2 & 39.1 & 0.35 & $<0.001$ & 23.4 & 17.7 & 16.9 & 20.1 & 0.001 \\
\hline
\end{tabular}

Age in mean (SD), all other results in percentage.

ACS, acute coronary syndrome; BMI, body mass index; CAD, coronary artery disease; CCI, Charlson comorbidity Index; STEMI, ST-elevation myocardial infarction. 
disease and dementia. Patients with ACS treated palliatively more frequently presented with atypical symptoms, less pain, dyspnoea, atrial fibrillation, NSTEMI and a higher Killip class.

Seventy-two per cent of all patients with ACS treated with reperfusion, $45 \%$ of all patients treated palliatively and $45 \%$ of all those treated conservatively were admitted to hospitals with catheter laboratory facilities. For patients treated palliatively, the delay between symptom onset and admission was much longer than the reperfusion group but shorter than the conservative group. Furthermore, more than one-third of the patients treated palliatively $(36.3 \%)$ were on anticoagulants before admission in comparison to those treated conservatively $(6.4 \%)$ and those who underwent reperfusion $(4.2 \%)$.

The percentage of patients with ACS treated without reperfusion continuously decreased between 1997 and 2013. Conservative treatment dropped from $53.3 \%$ to $10.3 \%$ and palliative treatment from $6 \%$ to $2 \%$ (figure 1 ). The percentage of patients with ACS who were palliatively treated increased with increased age (figure 2).

Comparison of the two periods (1997-2005 and 20062014) showed a significant decrease in the use of palliative therapy in patients with ACS, particularly in patients admitted with Killip class $>2$, from $11 \%$ to $5.9 \%$ ( $p$ for the test of homogeneity of the OR was 0.028 ). The same trend was seen for patients 75 years of age and younger, dropping from $2.2 \%$ to $1.1 \%$ ( $\mathrm{p}$ for the test of homogeneity of the OR was $<0.001$ ).

Trend analyses per quartile of time showed more females and patients with moderate to severe renal diseases received palliative treatment, but less resuscitated patients, less patients with typical symptoms, less patients with coronary artery disease and heart failure and less patients who presented with STEMI or acute decompensation (table 2). Additionally, comparisons of the temporal trends of patients treated palliatively and those who underwent reperfusion showed significant differences in the trends of gender, age, resuscitation, typical symptoms, Killip classes above 2, dyslipidaemia and smoking, as well as heart failure and comorbidities (table 2).

Patients treated palliatively compared with patients treated with antiplatelets and/or reperfusion were at greater risk of developing cardiogenic shock during hospitalisation $(16 \%$ vs $5 \% ; \mathrm{p}<0.001)$ and stroke $(2 \%$ vs $1 \%$; $\mathrm{p}=0.001)$, while bleeding $(2.0 \%$ vs $2.6 \%$; $\mathrm{p}=0.36)$ and reinfarction in-hospital were similar $(2.3 \%$ vs $1.7 \% ; \mathrm{p}=0.18)$. Crude in-hospital mortality was $25.8 \%$ in the palliative group compared with $5.6 \%$ for the others $(\mathrm{p}<0.001)$ and MACCE (27.4\% vs $7.2 \%$; $<<0.001$; figure 3 ). The median length of stay was 9 days (IQR 5-15 days) for the palliatively treated, 8 days (IQR 4-13 days) for the conservatively treated and 5 days (IQR 2-9 days) for the reperfusion patients $(p<0.001)$. Of the palliatively treated patients who survived hospital stay $(\mathrm{n}=1102), 225$ (20.4\%) were discharged home with homecare assistance or transferred to

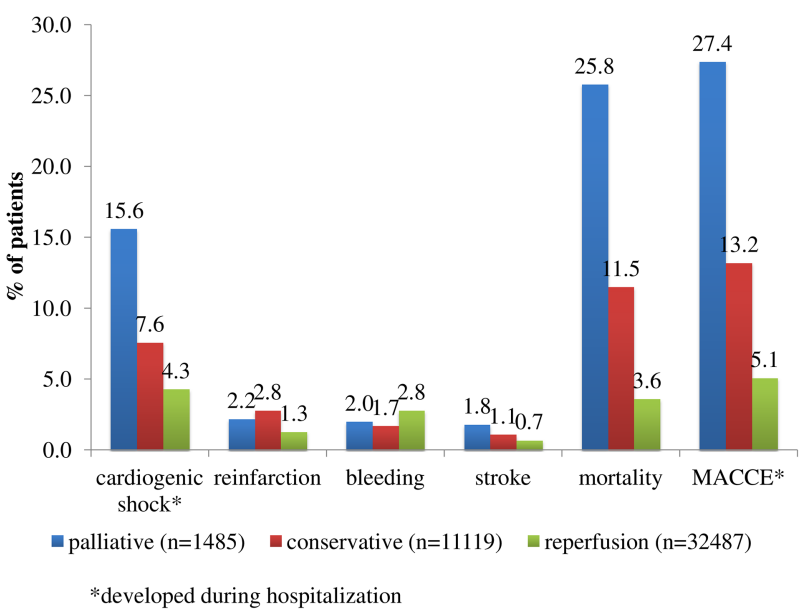

Figure 3 In-hospital complications and outcomes according to therapies received during the index hospitalisation. Cardiogenic shock-developing during hospitalisation. MACCE-major adverse cardiac and cerebrovascular events in-hospital—composite end point of reinfarction, stroke or death.

a retirement or nursing home compared with $10.4 \%$ of conservatively treated patients (1005/9841) and 1.5\% (464/31 318) of patients who underwent reperfusion.

In-hospital mortality decreased significantly between 1997 and 2013 in the groups of patients treated palliatively or with reperfusion, but not in those treated conservatively (table 3 ).

Since 2006, a subgroup of patients with ACS was followed 1 year after discharge. From a total of 22926 patients who could have possibly been included in the follow-up, 10770 (47\%) were asked to take part. Of these patients, $1912(17.8 \%)$ refused their consent leaving 8858 patients available for follow-up. The follow-up interview was consequently carried out with 8316 patients: $143(1.7 \%)$ patients had been treated palliatively, $1244(15 \%)$ conservatively and 6929 (83.3\%) had received reperfusion treatment during the index hospitalisation. The outcomes of these patients 1 year after discharge are shown in figure 4.

Patients admitted for ACS and treated palliatively suffered reinfarction $(9.2 \%$ vs $3.4 \%$ in others; $\mathrm{p}=0.003)$ more frequently and died more often during the first year after discharge $(14.0 \%$ vs $3.5 \%$; $\mathrm{p}<0.001)$.

There were no significant differences in mortality 1 year after discharge over time across the three treatment groups (table 4).

\section{DISCUSSION}

This study provides evidence that the population which received palliative therapy is older and sicker when compared with patients who underwent conservative or reperfusion treatment and the percentage of palliatively treated patients increased with age. Adding days and weeks to a life is not the only goal but to add quality of 

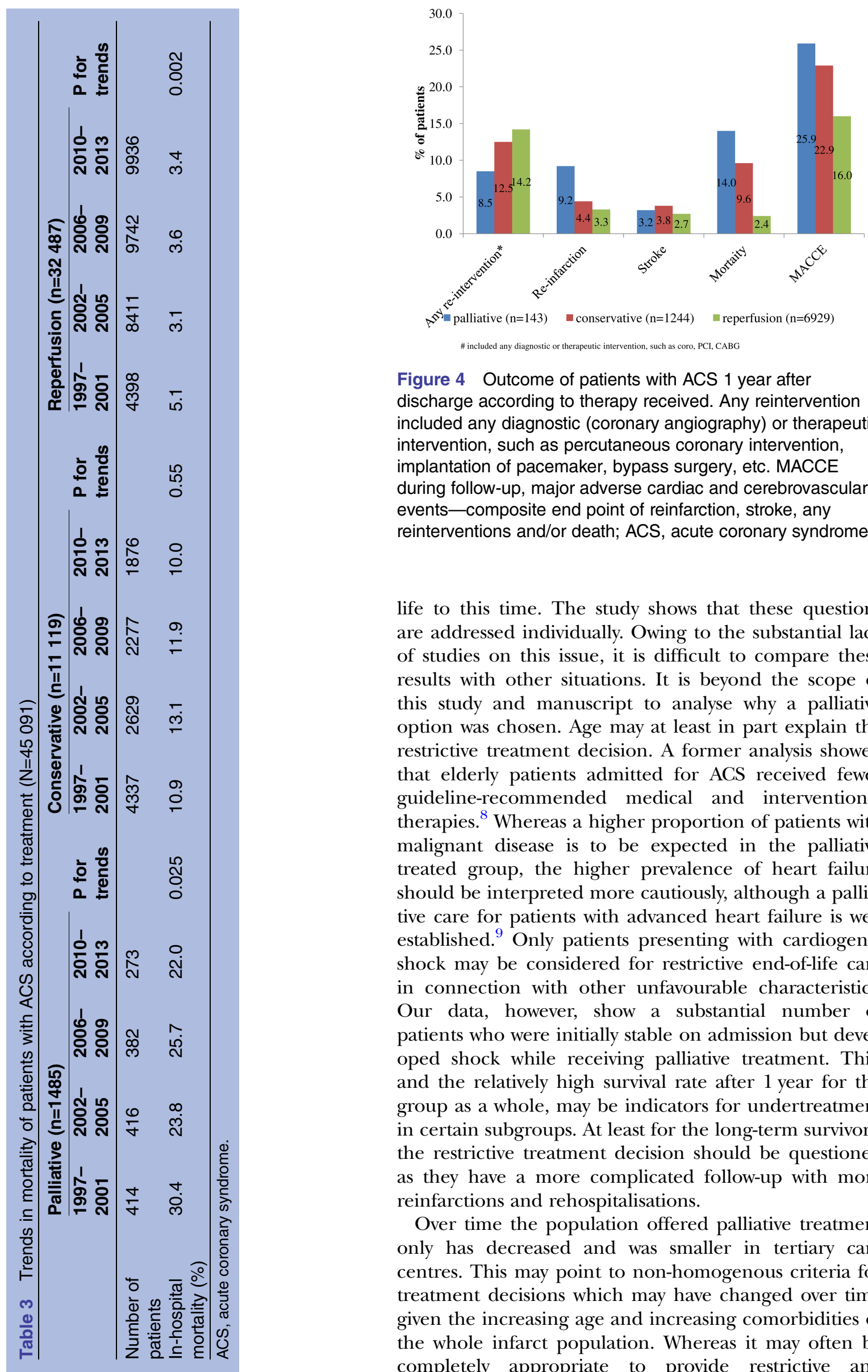

Figure 4 Outcome of patients with ACS 1 year after discharge according to therapy received. Any reintervention included any diagnostic (coronary angiography) or therapeutic intervention, such as percutaneous coronary intervention, implantation of pacemaker, bypass surgery, etc. MACCE during follow-up, major adverse cardiac and cerebrovascular events-composite end point of reinfarction, stroke, any reinterventions and/or death; ACS, acute coronary syndrome.

life to this time. The study shows that these questions are addressed individually. Owing to the substantial lack of studies on this issue, it is difficult to compare these results with other situations. It is beyond the scope of this study and manuscript to analyse why a palliative option was chosen. Age may at least in part explain the restrictive treatment decision. A former analysis showed that elderly patients admitted for ACS received fewer guideline-recommended medical and interventional therapies. ${ }^{8}$ Whereas a higher proportion of patients with malignant disease is to be expected in the palliative treated group, the higher prevalence of heart failure should be interpreted more cautiously, although a palliative care for patients with advanced heart failure is well established. ${ }^{9}$ Only patients presenting with cardiogenic shock may be considered for restrictive end-of-life care in connection with other unfavourable characteristics. Our data, however, show a substantial number of patients who were initially stable on admission but developed shock while receiving palliative treatment. This, and the relatively high survival rate after 1 year for the group as a whole, may be indicators for undertreatment in certain subgroups. At least for the long-term survivors, the restrictive treatment decision should be questioned as they have a more complicated follow-up with more reinfarctions and rehospitalisations.

Over time the population offered palliative treatment only has decreased and was smaller in tertiary care centres. This may point to non-homogenous criteria for treatment decisions which may have changed over time given the increasing age and increasing comorbidities of the whole infarct population. Whereas it may often be completely appropriate to provide restrictive and 
Table 4 Trends in mortality of patients with ACS according to treatment 1 year after discharge $(\mathrm{N}=8316)$

\begin{tabular}{|c|c|c|c|c|c|c|c|c|c|c|c|c|}
\hline & \multicolumn{4}{|c|}{ Palliative $(n=143)$} & \multicolumn{4}{|c|}{ Conservative $(n=1244)$} & \multicolumn{3}{|c|}{ Reperfusion ( $n=6929)$} & \multirow[b]{2}{*}{$\begin{array}{l}P \text { for } \\
\text { trends }\end{array}$} \\
\hline & $\begin{array}{l}\text { 2002- } \\
2005\end{array}$ & $\begin{array}{l}2006- \\
2009\end{array}$ & $\begin{array}{l}2010- \\
2013\end{array}$ & $\begin{array}{l}P \text { for } \\
\text { trends }\end{array}$ & $\begin{array}{l}\text { 2002- } \\
2005\end{array}$ & $\begin{array}{l}2006- \\
2009\end{array}$ & $\begin{array}{l}2010- \\
2013\end{array}$ & $\begin{array}{l}\text { P for } \\
\text { trends }\end{array}$ & $\begin{array}{l}2002- \\
2005\end{array}$ & $\begin{array}{l}2006- \\
2009\end{array}$ & $\begin{array}{l}2010- \\
2013\end{array}$ & \\
\hline Number of patients & 28 & 83 & 32 & & 171 & 707 & 366 & & 734 & 3824 & 2371 & \\
\hline $\begin{array}{l}\text { Mortality } 1 \text { year after } \\
\text { discharge }(\%)\end{array}$ & 21.4 & 12.0 & 12.5 & 0.34 & 12.3 & 9.5 & 8.7 & 0.24 & 1.8 & 2.2 & 2.8 & 0.067 \\
\hline
\end{tabular}

palliative care only for elderly patients with a very poor prognosis, our analysis shows a much larger grey zone of decision-making. This warrants further investigation.

To the best our knowledge, there are no systematic data available on patients with ACS who were not given active therapy for whatever reason. There are few case reports with regard to treatment of patients with MI and concomitant severe cancer diseases. ${ }^{10}{ }^{11}$ Fenning et al ${ }^{12}$ used two prognostic tools (Golden Standards Framework and GRACE Score) to identify patients with ACS approaching end of life and who were therefore eligible for palliative care. The patients with ACS identified as requiring end-of-life care were older, had more comorbidities, were more likely to be readmitted during follow-up and had higher mortality than those who did not meet these criteria. This is in accordance with our results, which showed that palliatively treated patients suffered reinfarction more frequently during the 1 year period after discharge.

This raises the question of whether an effort is necessary to improve compliance by also strictly adhering to guidelines for patients where analgesic therapy only would be the most humane approach. The second question is how these palliative patients impact the quality control and benchmarking processes. According to the results of this study, the overall crude in-hospital mortality of all patients with ACS during the past 17 years was $6.3 \%$, but after exclusion of the patients treated palliatively this was significantly lower with a mortality rate of $5.6 \%$.

\section{Limitations}

An important limitation of our study is the lack of evidence for the exact reasons to withhold active therapy and to treat palliatively only. We did not analyse the reasons for choosing 'palliative care' as the initial strategy and thereby withholding prognostic favourable treatment options to these patients; nor do we have the means to do this at random. Analysis of such decisionmaking under time pressure involving medical perspectives (age, comorbidity) and patient's wishes and their quality of life equally is beyond the scope of an infarction registry, and we accept that there are good reasons for deciding on palliative treatment for some patients.

However, it would be almost impossible to gain reliable data on decision-making in the context of a national registry. Furthermore, some misclassifications cannot be excluded due to the fact that some palliatively treated patients died before they could be treated invasively.

Our study should also be interpreted in the context of the following limitations: the weaknesses of AMIS Plus are common to all registries. Participation in the AMIS Plus registry is voluntary; the number of hospitals varied over the years and this might have caused an unrecognised exclusion bias in patients treated palliatively. However, the large number of patients and the longlasting continuous collection of data involving more than $75 \%$ of Swiss hospitals treating patients with ACS enable analysis of the observed data. Data quality was checked by external audits.

\section{CONCLUSIONS}

Patients with ACS treated palliatively were older, sicker, with more heart failure at admission and very high in-hospital mortality. Changes of treatment decisions over time and the proportion of patients surviving 1 year suggest in part non-homogenous and potentially questionable decision criteria. While refraining from more active therapy may be the most humane and appropriate approach in many patients, in others it represents under treatment. In any case, this patient group warrants further study and should be included in outcome statistics and registries.

\section{Author affiliations \\ ${ }^{1}$ AMIS Plus Data Center, Epidemiology, Biostatistics and Prevention Institute, University of Zurich, Zurich, Switzerland \\ ${ }^{2}$ Department of Cardiology, Clinic St. Anna, Lucerne and University Hospital Zurich, Zurich, Switzerland \\ ${ }^{3}$ Department of Biostatistics, Epidemiology, Biostatistics and Prevention Institute, University of Zurich, Zurich, Switzerland \\ ${ }^{4}$ Cardiology Centre, Klinik Im Park, Zurich, Switzerland \\ ${ }^{5}$ Cardiovascular Department, Hôpital de La Tour, Geneva, Switzerland}

Acknowledgements The authors would like to thank our sponsors for their financial support. They also thank Jenny Piket for proofreading this manuscript.

Collaborators AMIS Plus Participants 1997-2014: The authors would like to express their gratitude to the teams of the following hospitals (listed in alphabetical order with the names of the local principal investigators): Aarau, Kantonsspital (P Lessing), Affoltern am Albis, Spital (F Hess), Altdorf, Kantonsspital Uri (R Simon), Altstätten, Spital (PJ Hangartner), Baden, Kantonsspital (U Hufschmid), Basel, St. Claraspital (B Hornig), Basel, Universitätsspital (R Jeger), Bern, Beau-Site Klinik (S Trummler), Bern, Inselspital (S Windecker), Bern, Hirslanden Salem-Spital (T Rueff), Bern, 
Tiefenauspital (P Loretan), Biel, Spitalzentrum (C Roethlisberger), Brig-Glis, Oberwalliser Kreisspital (D Evéquoz), Bülach, Spital (G Mang), Burgdorf, Regionalspital Emmental (D Ryser), Chur, Rätisches Kantons- und Regionalspital (P Müller), Chur, Kreuzspital (R Jecker), Davos, Spital (W Kistler), Dornach, Spital (A. Droll), Einsiedeln, Regionalspital (S Stäuble), Flawil, Spital (G Freiwald), Frauenfeld Kantonsspital (HP Schmid), Fribourg, Hôpital cantonal (JC Stauffer/S Cook), Frutigen, Spital (K Bietenhard), Genève, Hôpitaux universitaires (M Roffi), Glarus, Kantonsspital (W. Wojtyna), Grenchen, Spital (R Schönenberger), Grosshöchstetten, Bezirksspital (C Simonin), Heiden, Kantonales Spital (R Waldburger), Herisau, Kantonales Spital (M Schmidli), Horgen, See Spital (B Federspiel), Interlaken, Spital (EM Weiss), Jegenstorf, Spital (H Marty), Kreuzlingen, Herzzentrum Bodensee (K Weber), La Chaux-de-Fonds, Hôpital (H Zender), Lachen, Regionalspital (I Poepping), Langnau im Emmental, Regionalspital (A Hugi), Laufenburg, Gesundheitszentrum Fricktal (E Koltai), Lausanne, Centre hospitalier universitaire vaudois (JF Iglesias), Lugano, Cardiocentro Ticino (G Pedrazzini), Luzern, Luzerner Kantonsspital (P Erne, Luzern, 1997-2013, presently at St. Anna, Luzern, 2014- F. Cuculi), Männedorf, Kreisspital (T Heimes), Martigny, Hôpital régional (B Jordan), Mendrisio, Ospedale regionale (A Pagnamenta), Meyrin, Hôpital de la Tour (P Urban), Monthey, Hôpital du Chablais (P Feraud), Montreux, Hôpital de Zone (E Beretta), Moutier, Hôpital du Jura bernois (C Stettler), Münsingen, Spital (F Repond), Münsterlingen, Kantonsspital (F Widmer), Muri, Kreisspital für das Freiamt (C Heimgartner), Nyon, Group. Hosp. Ouest lémanique (R Polikar), Olten, Kantonsspital (S Bassetti), Rheinfelden, Gesundheitszentrum Fricktal (HU Iselin), Rorschach, Spital (M Giger), Samedan, Spital Oberengadin (P Egger), Sarnen, Kantonsspital Obwalden (T Kaeslin), Schaffhausen, Kantonsspital (A Fischer), Schlieren, Spital Limmattal (T Herren), Schwyz, Spital ( $P$ Eichhorn), Scuol, Ospidal d'Engiadina Bassa (C Neumeier/G Flury), Sion, Hôpital du Valais (G Girod), Solothurn, Bürgerspital (R Vogel), Stans, Kantonsspital Nidwalden (B Niggli), St. Gallen, Kantonsspital (H Rickli), Sursee, Luzerner Kantonsspital (Se-I Yoon, -2013, J Nossen, 2014-), Thun, Spital (U Stoller), Thusis, Krankenhaus (UP Veragut), Uster, Spital (E Bächli), Uznach, Spital Linth (A Weber), Walenstadt, Kantonales Spital (D Schmidt/J Hellermann), Wetzikon, GZO Spital (U Eriksson), Winterthur, Kantonsspital (T Fischer), Wolhusen, Luzener Kantonsspital (M Peter), Zofingen, Spital (S Gasser), Zollikerberg, Spital (R Fatio), Zug, Kantonsspital (M Vogt/D Ramsay), Zürich, Hirslanden Klinik im Park (0 Bertel), Zürich, Universitätsspital (M Maggiorini), Zürich, Stadtspital Triemli (F Eberli), Zürich, Stadtspital Waid (S Christen).

Contributors PE contributed to the conception and design, acquisition of data and critical revision of manuscript for intellectual content. DR contributed to conception and design, analysis and interpretation of data and drafting of the article. BS contributed to analysis and interpretation of data, and a critical revision of the manuscript. $\mathrm{OB}$ and $\mathrm{PU}$ contributed to acquisition of data and a critical revision of the manuscript for intellectual content.

Funding The AMIS Plus registry is funded by unrestricted grants from the Swiss Heart Foundation and from Abbot AG, Switzerland; AMGEN Switzerland AG, Switzerland; Astra-Zeneca AG, Switzerland; Bayer (Schweiz) AG, Switzerland; Biotronik AG, Switzerland; Bristol-Myers Squibb AG, Switzerland; Daiichi-Sankyo/Lilly AG, Switzerland; Johnson \& Johnson AG-Cordis Division, Switzerland; A Menarini AG, Switzerland; Merck Sharp \& Dohme-Chibret AG,
Switzerland; Medtronic AG, Switzerland; Pfizer AG, Switzerland; SISMedical AG, Switzerland; St. Jude Medical, Switzerland; Takeda Pharma AG, Switzerland; Vascular Medical AG, Switzerland.

Competing interests None.

Ethics approval The registry was approved by the Supra-Regional Ethics Committee for Clinical Studies, the Swiss Board for Data Security and the all Cantonal Ethics Commissions.

Provenance and peer review Not commissioned; externally peer reviewed.

Data sharing statement No additional data are available.

Open Access This is an Open Access article distributed in accordance with the Creative Commons Attribution Non Commercial (CC BY-NC 4.0) license, which permits others to distribute, remix, adapt, build upon this work noncommercially, and license their derivative works on different terms, provided the original work is properly cited and the use is non-commercial. See: http:// creativecommons.org/licenses/by-nc/4.0/

\section{REFERENCES}

1. Radovanovic D, Erne P. AMIS Plus: Swiss registry of acute coronary syndrome. Heart 2010;96:917-21.

2. Radovanovic D, Nallamothu BK, Seifert B, et al. Temporal trends in treatment of ST-elevation myocardial infarction among men and women in Switzerland between 1997 and 2011. Eur Heart J Acute Cardiovasc Care 2012;1:183-91.

3. Witassek F, Schwenkglenks M, Erne P, et al. Impact of body mass index on mortality in Swiss hospital patients with ST-elevation myocardial infarction: does an obesity paradox exist? Swiss Med Wkly 2014;144:w13986.

4. Charlson ME, Pompei P, Ales KL, et al. A new method of classifying prognostic comorbidity in longitudinal studies: development and validation. J Chronic Dis 1987;40:373-83.

5. Radovanovic D, Seifert B, Urban P, et al. Validity of Charlson Comorbidity Index in patients hospitalised with acute coronary syndrome. Insights from the nationwide AMIS Plus registry 20022012. Heart 2014;100:288-94.

6. Thygesen K, Alpert JP, White HD, et al. Universal definition of myocardial infarction. Eur Heart J 2007;28:2525-38.

7. Urban $P$, Radovanovic $D$, Erne $P$, et al. Impact of changing definitions for myocardial infarction: a report from the AMIS registry. Am J Med 2008;121:1065-71.

8. Schoenenberger AW, Radovanovic D, Stauffer JC, et al. Age-related differences in the use of guideline-recommended medical and interventional therapies for acute coronary syndromes: a cohort study. J Am Geriatr Soc 2008;56:510-16.

9. Jaarsma T, Beattie JM, Ryder M, et al. Palliative care in heart failure a position statement from the palliative care workshop of the Heart Failure Association of the European Society of Cardiology. Eur J Heart Fail 2009;11:433-43.

10. Jao GT, Knovich MA, Savage RW, et al. ST-elevation myocardial infarction and myelodysplastic syndrome with acute myeloid leukemia transformation. Tex Heart Inst J 2014;41:234-7.

11. Vastbinder MB, Drost $\mathrm{H}$, Muller EW. [Acute coronary syndrome after chemotherapy]. Ned Tijdschr Geneeskd 2014;158:A6940.

12. Fenning $\mathrm{S}$, Woolcock $\mathrm{R}$, Haga $\mathrm{K}$, et al. Identifying acute coronary syndrome patients approaching end-of-life. PLOS ONE 2012;7: e35536. 